\title{
Predictive value of dobutamine echocardiography and positron emission tomography in identifying hibernating myocardium in patients with postischaemic heart failure
}

\author{
D Pagano, R S Bonser, J N Townend, F Ordoubadi, R Lorenzoni, P G Camici
}

\begin{abstract}
Objective-To compare the predictive value of dobutamine echocardiography (DE) and positron emission tomography (PET) in identifying reversible chronic left ventricular (LV) dysfunction (hibernating myocardium) in patients with coronary artery disease (CAD) and overt heart failure.

Patients-30 patients (four women) with CAD and heart failure undergoing coronary artery bypass grafting (CABG). Methods-Myocardial viability was assessed with DE ( 5 and $10 \mu \mathrm{g} / \mathrm{kg} / \mathrm{min}$ ) and PET with $\left[{ }^{18} \mathrm{~F}\right]$ 2-fluoro-2-deoxy-Dglucose (FDG) under hyperinsulinaemic euglycaemic clamp. Regional (echo) and global LV function (MUGA) were assessed at baseline and six months after CABG.

Results-192 of the 336 (57\%) dysfunctional LV segments improved function following CABG (hibernating) and the $L V$ ejection fraction (EF) increased from $23(7)$ to $32(9) \%(p<0.0001)$ (in 17 patients $>5 \%$ ). DE and PET had similar positive predictive values $(68 \%$ and $66 \%)$ in the identification of hibernating myocardium, but DE had a significantly lower negative predictive value than PET (54\% v 96\%; p $<0.0001)$. A significant linear correlation was found between the number of PET viable segments and the changes in EF following CABG $(r=0.65 ; p=0.0001)$. Stepwise logistic regression identified the number of PET viable segments as an independent predictor of improvement in EF $>5 \%$, whereas the number of DE viable segments, the baseline LVEF, and wall motion were not.
\end{abstract}

Conclusions-DE has a higher false negative rate than PET in identifying recoverable $L V$ dysfunction in patients with severe postischaemic heart failure. The amount of PET viable myocardium correlates with the functional outcome following CABG. (Heart 1998;79:281-288)

Keywords: dobutamine echocardiography; positron emission tomography; coronary artery disease; heart failure; hibernating myocardium Professor Camici, MRC Cyclotron Unit,

Hammersmith Hospital,

Ducane Road, London W12

ONN, UK. email:

paolo@cu.rpms.ac.uk

Accepted for publication 15 December 1977
In patients with coronary artery disease (CAD), dysfunctional left ventricular (LV) segments subtended by a stenotic coronary artery can recover contractile function follow- ing revascularisation and this myocardium has been defined as hibernating. ${ }^{12}$ The revascularisation of hibernating myocardium is associated with improvement in LV function ${ }^{34}$ in patients with CAD, and recent studies have suggested that patients with non-revascularised hibernating myocardium have a propensity to suffer adverse cardiac events. ${ }^{56}$ The condition of myocardial hibernation raises the possibility that patients with severe LV impairment and heart failure may benefit from revascularisation and the correct preoperative identification of recoverable LV dysfunction may reduce their risk of surgery. ${ }^{7}$

The presence of hibernating myocardium can be predicted by non-invasive imaging techniques such as positron emission tomography (PET) with $\left[{ }^{18} \mathrm{~F}\right]$ 2-fluoro-2-deoxy-D-glucose (FDG), thallium-201 scintigraphy, and dobutamine echocardiography (DE). These methods probe different mechanisms associated with cellular viability such as preserved myocardial uptake of exogenous glucose for PET, sarcolemmal integrity for thallium-201, and the presence of inotropic contractile reserve on stimulation of $\beta$ adrenoceptors for $\mathrm{DE} .^{8} \mathrm{DE}$ is usually the initial approach for the identification of hibernating myocardium because it is inexpensive, widely available, and has a good predictive value. ${ }^{9}$ However, there is some evidence that in severely dysfunctional myocardium DE yields a lower negative predictive value (higher false negative rate) than PET or thallium-201 scintigraphy. ${ }^{10-14}$ Thus, patients with heart failure and hibernating myocardium might be missed by DE and denied the potential benefits of revascularisation.

This study aimed at comparing the predictive value of DE and PET in identifying hibernating myocardium in patients with chronic $\mathrm{CAD}$ and severe $\mathrm{LV}$ dysfunction resulting in overt heart failure.

\section{Methods}

PATIENTS

The study population was 30 patients (four women, mean (SD) age 57 (7) years, with multivessel CAD and stable chronic heart failure (New York Heart Association (NYHA) class $\geqslant$ III). These patients were part of a study investigating the role of CABG in postischaemic heart failure in which patients with angina (irrespectively of the demonstration of viability) and those without angina but with significant viability underwent CABG, and patients with no angina or exercise inducible 
Table 1 Patient characteristics

\begin{tabular}{|c|c|c|c|c|c|c|c|c|c|c|c|c|c|}
\hline \multirow[b]{2}{*}{ Patient } & \multirow[b]{2}{*}{ Age } & \multirow[b]{2}{*}{ Sex } & \multicolumn{8}{|l|}{ Baseline } & \multicolumn{3}{|c|}{ Follow up } \\
\hline & & & NYHA & $C A D$ & $C A B G$ & $\begin{array}{l}E F \\
(\%)\end{array}$ & WMSI & $D S$ & $\begin{array}{l}\text { PET } \\
\text { viable }\end{array}$ & $\begin{array}{l}\mathrm{DE} \\
\text { viable }\end{array}$ & NYHA & $\begin{array}{l}E F \\
(\%)\end{array}$ & WMSI \\
\hline 1 & 45 & M & $\mathrm{III}^{\star}$ & $\begin{array}{l}\mathrm{LAD}, \mathrm{CX}, \\
\mathrm{RCA}\end{array}$ & 3 & 32 & 1.8 & 9 & 9 & 9 & I & 54 & 1.1 \\
\hline 2 & 49 & M & IV & $\begin{array}{l}\mathrm{LAD}, \mathrm{CX}, \\
\mathrm{RCA}\end{array}$ & 4 & 17 & 2.3 & 14 & 14 & 9 & I & 24 & 1.6 \\
\hline 3 & 41 & $\mathrm{~F}$ & $\mathrm{III}^{\star}$ & $\begin{array}{l}\mathrm{LAD}, \mathrm{CX}, \\
\mathrm{RCA}\end{array}$ & 2 & 37 & 1.8 & 12 & 5 & 9 & I & 29 & 1.7 \\
\hline 4 & 57 & M & III & $\mathrm{LAD}, \mathrm{CX}$ & 2 & 23 & 2.3 & 15 & 13 & 8 & I & 38 & 1.5 \\
\hline 5 & 54 & M & III & $\begin{array}{l}\text { LAD, CX, } \\
\text { RCA }\end{array}$ & 3 & 30 & 1.8 & 10 & 9 & 7 & $\mathrm{I}$ & 42 & 1.1 \\
\hline 6 & 59 & M & III & $\begin{array}{l}\mathrm{LAD}, \mathrm{CX}, \\
\mathrm{RCA}\end{array}$ & 4 & 26 & 2.4 & 15 & 15 & 7 & I & 56 & 1.5 \\
\hline 7 & 66 & M & IV & $\begin{array}{l}\text { LAD, CX, } \\
\text { RCA }\end{array}$ & 2 & 21 & 2.5 & 11 & 11 & 4 & II & 32 & 1.5 \\
\hline 8 & 50 & $M$ & III & $\begin{array}{l}\text { LAD, CX, } \\
\text { RCA }\end{array}$ & 3 & 37 & 2.3 & 10 & 6 & 4 & I & 38 & 2.0 \\
\hline 9 & 50 & $M$ & IV & $\begin{array}{l}\text { LAD, CX, } \\
\text { RCA }\end{array}$ & 3 & 30 & 2.2 & 13 & 13 & 9 & II & 41 & 1.6 \\
\hline 10 & 68 & M & III & $\begin{array}{l}\text { LAD, CX, } \\
\text { RCA }\end{array}$ & 3 & 15 & 2.2 & 7 & 7 & 5 & I & 21 & 1.6 \\
\hline 11 & 50 & $M$ & III & $\begin{array}{l}\text { LAD, CX, } \\
\text { RCA }\end{array}$ & 2 & 21 & 2.1 & 13 & 13 & 7 & II & 23 & 1.9 \\
\hline 12 & 68 & M & $\mathrm{III}^{\star}$ & $\begin{array}{l}\text { LAD, CX, } \\
\text { RCA }\end{array}$ & 4 & 25 & 2.6 & 9 & 4 & 4 & II & 18 & 2.5 \\
\hline 13 & 48 & M & IV & $\begin{array}{l}\text { LAD, CX, } \\
\text { RCA }\end{array}$ & 3 & 19 & 2.1 & 10 & 9 & 4 & II & 25 & 1.9 \\
\hline 14 & 65 & $\mathrm{~F}$ & III & $\begin{array}{l}\text { LAD, CX, } \\
\text { RCA }\end{array}$ & 3 & 37 & 1.6 & 9 & 8 & 3 & II & 40 & 1.4 \\
\hline 15 & 63 & $M$ & III & LAD, CX & 3 & 20 & 2.3 & 12 & 12 & 6 & I & 28 & 1.5 \\
\hline 16 & 57 & $M$ & III & $\begin{array}{l}\text { LAD, CX, } \\
\text { RCA }\end{array}$ & 3 & 22 & 2.6 & 14 & 13 & 11 & I & 37 & 1.6 \\
\hline 17 & 66 & M & III & $\begin{array}{l}\text { LAD, CX, } \\
\text { RCA }\end{array}$ & 4 & 21 & 2.0 & 7 & 7 & 5 & II & 25 & 1.4 \\
\hline 18 & 72 & $\mathrm{~F}$ & III & $\begin{array}{l}\text { LAD, CX, } \\
\text { RCA }\end{array}$ & 3 & 19 & 2.6 & 15 & 15 & 8 & II & 26 & 1.9 \\
\hline 19 & 57 & M & III & LAD, CX & 1 & 25 & 2.3 & 14 & 14 & 3 & II & - & 2.1 \\
\hline 20 & 62 & $M$ & IV & $\begin{array}{l}\text { LAD, CX, } \\
\text { RCA }\end{array}$ & 3 & 10 & 2.5 & 13 & 13 & 4 & I & 29 & 1.9 \\
\hline 21 & 66 & $\mathrm{M}$ & III & $\begin{array}{l}\mathrm{LAD}, \mathrm{CX}, \\
\mathrm{RCA}\end{array}$ & 4 & 22 & 2.7 & 15 & 15 & 10 & I & 36 & 1.5 \\
\hline 22 & 60 & M & III & $\begin{array}{l}\mathrm{LAD}, \mathrm{CX}, \\
\mathrm{RCA}\end{array}$ & 5 & 18 & 2.4 & 15 & 12 & 4 & II & 24 & 2.0 \\
\hline 23 & 55 & $\mathrm{~F}$ & $\mathrm{III}^{\star}$ & $\begin{array}{l}\text { LAD, CX, } \\
\text { RCA }\end{array}$ & 4 & 27 & 1.7 & 10 & 10 & 7 & II & 29 & 1.8 \\
\hline 24 & 59 & M & III & $\mathrm{LAD}, \mathrm{CX}$ & 3 & 26 & 2.5 & 15 & 14 & 10 & I & 38 & 1.5 \\
\hline 25 & 59 & M & III & $\begin{array}{l}\text { LAD, CX, } \\
\text { RCA }\end{array}$ & 4 & 25 & 2.0 & 9 & 8 & 3 & I & 39 & 1.7 \\
\hline 26 & 53 & $\mathrm{M}$ & $\mathrm{III}^{\star}$ & $\begin{array}{l}\text { LAD, CX, } \\
\text { RCA }\end{array}$ & 2 & 35 & 1.8 & 4 & 0 & 0 & I & 35 & 1.8 \\
\hline 27 & 65 & M & $\mathrm{III}^{\star}$ & $\begin{array}{l}\text { LAD, CX, } \\
\text { RCA }\end{array}$ & 3 & 23 & 2.2 & 12 & 0 & 2 & II & 22 & 2.2 \\
\hline 28 & 63 & $\mathrm{M}$ & $\mathrm{III}^{\star}$ & $\begin{array}{l}\text { LAD, CX, } \\
\text { RCA }\end{array}$ & 3 & 20 & 2.1 & 10 & 10 & 6 & I & 25 & 1.6 \\
\hline 29 & 48 & $\mathrm{M}$ & $\mathrm{III}^{\star}$ & $\begin{array}{l}\mathrm{LAD}, \mathrm{CX}, \\
\mathrm{RCA}\end{array}$ & 4 & 32 & 1.9 & 7 & 4 & 0 & I & 33 & 1.9 \\
\hline 30 & 49 & M & $\mathrm{III}^{\star}$ & $\mathrm{LAD}, \mathrm{CX}$ & 4 & 35 & 1.8 & 7 & 3 & 1 & I & 36 & 1.8 \\
\hline
\end{tabular}

$\star$ Patient had angina symptoms.

NYHA, New York Heart Association functional class; CAD, coronary artery disease ( $>70 \%$ stenosis); LAD, left anterior descending; CX, circumflex; RCA, right coronary artery; CABG, coronary artery bypass grafting including branches of main epicardial vessels; EF, left ventricular ejection fraction; WMSI, wall motion score index; DS, dysfunctional left ventricular segments.

ischaemia and no evidence of viable myocardium (both at PET and DE) were excluded. ${ }^{15}$ All patients were in sinus rhythm and had suffered at least one (range 1-3) Q wave myocardial infarction a mean (SD) of 30 (14) months (range 12-60) before the study. Nine patients had mild effort angina. Seven patients were diabetic and five hypertensive. Patients were receiving treatment with angiotensin converting enzyme (ACE) inhibitors (25), diuretics (18), digoxin (7), nitrates (7), and calcium channel blockers (3). No patient was on $\beta$ blockers. All medical treatment was withdrawn on the study day both at baseline and follow up. The radionuclide $\mathrm{LV}$ ejection fraction (EF) was $25(7) \%$ (range $10-37 \%$ ). Table 1 shows the baseline characteristics of the patient population.
The study was approved by the local ethics committee and written informed consent was obtained from all the patients. The radiation exposure was licensed by the UK Administration of Radioactive Substances Advisory Committee (ARSAC).

STUDY PROTOCOL

All patients had assessment of viability before CABG with PET and DE, and assessment of regional and global LV function before and six months after CABG.

Assessment of LV function

MUGA-All patients underwent radionuclide ventriculography ${ }^{16}$ for the assessment of LVEF. Briefly, after red blood cells had been labelled in vivo with $740 \mathrm{MBq}$ of technetium $-99^{\mathrm{m}}$ 
sodium pertechnetate, the intracardiac blood pool was imaged using a $\gamma$ camera (Siemens LEM+, Munich, Germany) equipped with a low energy all purpose collimator and interfaced with a dedicated computer system (Nuclear Diagnostics, Gravesend, UK). Data for each cardiac cycle, synchronised to the $\mathrm{R}$ wave on the electrocardiogram, were divided into 32 frames. Six million counts for each view were acquired. Planar blood pool imaging was performed in the left anterior oblique projection with up to a $20^{\circ}$ caudal tilt (best septal separation). The analysis was performed by two experienced, independent physicians who were blinded to all clinical details including the preoperative or postoperative status. The analysis was performed using a commercially available computer program (Hermes Gated Heart Analysis FUGA, Nuclear Diagnostics), which automatically allocates a region for background subtraction. In each case the position of such a region was checked and relocated appropriately (away from cardiac chambers or great vessels) when necessary. The interobserver and intraobserver agreement was assessed in a random subset of 10 patients using the method described by Bland and Altman. ${ }^{17}$ The mean (SD) of the differences in LVEF was $0.05(1.5) \%$ points and the $95 \%$ confidence intervals (CI) were $-2.9 \%$ to $3 \%$.

Transthoracic echocardiography-Segmental LV wall motion was assessed by transthoracic echocardiography (HP Sonos 2500, Hewlett Packard, Andover, Massachusetts, USA) according to the recommendations of the American Society of Echocardiography. ${ }^{18}$ To circumvent the problem of postoperative paradoxical septal movement, wall thickening was used primarily for the assessment of septal segments. The wall motion was graded as 1 (normal), 2 (hypokinetic), 3 (akinetic), or 4 (dyskinetic). The wall motion score index (WMSI) was calculated as the sum of the scores of the left ventricular segments divided by the number of segments evaluated. ${ }^{18} \mathrm{~A}$ segment was considered as recovering contractile function following CABG if there was a reduction of at least 1 point in the wall motion/systolic thickening score.

Assessment of myocardial viability

Dobutamine echocardiography-After the baseline echocardiographic study, dobutamine infusion was started at $5 \mu \mathrm{g} / \mathrm{kg} / \mathrm{min}$ for five minutes and increased to $10 \mu \mathrm{g} / \mathrm{kg} / \mathrm{min}$ for an additional five minutes. Echocardiographic undigitised images for preoperative and postoperative wall motion and for the dobutamine study were analysed off-line from the videotape playback by continuous display by two independent operators unaware of all the clinical details of the patients. A dysfunctional LV segment was considered viable if infusion of dobutamine at 5 or $10 \mu \mathrm{g} / \mathrm{kg} / \mathrm{min}$ resulted either in improvement of wall motion/thickening of at least 1 point (inotropic contractile reserve) or deterioration of at least 1 point (ischaemia). In a random subset of 10 patients (160 segments), the interobserver and intraobserver agreements were assessed using the $\kappa$ agreement test: interobserver $\kappa=0.82(95 \%$ CI 0.69 to 0.95$)$; intraobserver $\kappa=0.90$ (95\% CI 0.80 to 1.00$)$. PET-FDG-Measurement of the rate of myocardial glucose utilisation (MRG) was carried out during hyperinsulinaemic euglycaemic clamp as described previously. ${ }^{19}$ Briefly, MRG was measured with the glucose analogue FDG, $185 \mathrm{MBq}$ of which were infused intravenously over two minutes. A 36-frame dynamic PET scan was performed over 65 minutes. Sinograms were corrected for tissue attenuation and reconstructed by computer using standard reconstruction algorithms. Images were resliced in the short axis view and the LV was divided into basal, mid, and apical regions. To define $16 \mathrm{LV}$ segments in the PET images, comparable to the ones used for the echo analysis, ${ }^{18}$ a radial divider comprising eight angular sectors of $45^{\circ}$ each, was superimposed on the short axis images and centred in the left ventricular cavity. The basal and mid-LV portions were divided into six segments (anterior and posterior septum, anterior, lateral, posterior, and inferior) and the apical portion was divided into four segments (anterior, lateral, inferior, and septum). A dysfunctional segment (hypokinetic or akinetic at echocardiography) was considered viable if the FDG uptake was $\geqslant 0.25 \mu \mathrm{mol} / \mathrm{min} / \mathrm{g}$ - that is, the mean myocardial tracer uptake minus 1 SD measured in normally contracting regions as reported previously. ${ }^{19} 20$

CABG

Surgery was performed by one surgeon using cardiopulmonary bypass, mild hypothermia $\left(32-34^{\circ} \mathrm{C}\right)$, and intermittent ischaemic arrest. The median number of grafts was three (range $1-5)$, the cardiopulmonary bypass time was 51 (14) minutes and the aortic clamp time 25 (6) minutes.

STATISTICAL ANALYSIS

The analysis was performed using a commercially available computer program (Arcus Quickstat; Research Solution, Cambridge, UK). Continuous data were expressed as mean (1 SD). Positive and negative predictive values, sensitivity, specificity, and accuracy were based on standard definitions. ${ }^{21}$ Comparison of paired data was made with the paired $t$ test. Categorical data were compared with the $\chi^{2}$ or Fisher's exact test as appropriate. Simple linear regression analysis with Pearson's correlation coefficient was performed to investigate the relation between two continuous variables. Improvement in global LV function was defined as an increase of $>5 \%$ points in $\mathrm{LVEF}^{4}{ }^{42}$ a value that constitutes the recognised variability in calculating EF with radionuclide ventriculography. Stepwise logistic regression analysis was performed to identify independent predictors of functional LV recovery. A backward-stepwise algorithm was used. Receiver operator characteristics (ROC) curve was derived according to the method described by Metz. ${ }^{21}$ When comparing ROC curves the area under the curve was used as the discriminator. ${ }^{21} \mathrm{~A} \mathrm{p}$ value $<0.05$ was considered significant. 

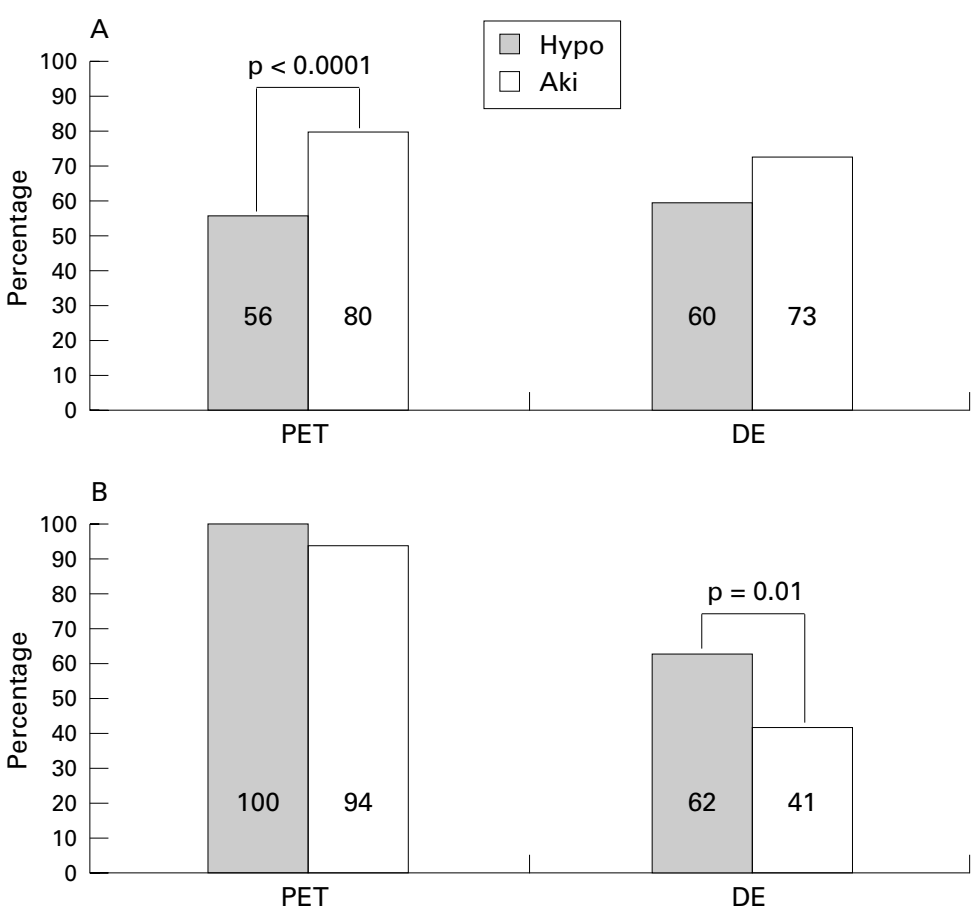

Figure 1 (A) Positive and (B) negative predictive values of PET and DE in hypokinetic (Hypo) and akinetic (Aki) left ventricular segments. Note in particular that the negative predictive value of $D E$ decreases in the more dysfunctional segments.

\section{Results}

BASELINE CHARACTERISTICS

Of $480 \mathrm{LV}$ segments, $27(5.6 \%)$ could not be assessed by either PET (13 segments) or DE (14 segments). Of the 453 segments assessed by both techniques, 28 were subtended by a normal and 425 by a stenotic (>70\%) coronary artery that was revascularised. Of these 425 segments, $89(21 \%)$ had normal baseline wall motion and $336(79 \%)$ were dysfunctional (180 hypokinetic and 156 akinetic). The mean number of dysfunctional segments for each patient was 11 (3) (range 7-15). The baseline LVEF was 25(7)\% and the WMSI was $2.18(0.3)$.

FUNCTIONAL OUTCOME

Six months after CABG there was an improvement in NYHA class in all patients (table 1), there was no recurrent angina, and no patient required hospitalisation for heart failure. To minimise the effects of medical treatment on the results, the heart failure medications (ACE inhibitors restarted three to seven days after CABG) were maintained unchanged throughout the study period with the exception of diuretics, the dose of which was reduced in eight patients. Antianginal medications were withdrawn at the time of CABG and no patient required antianginal treatment during follow up.

One patient was excluded from follow up radionuclide ventriculography as he manifested a predominant ventricular paced rhythm. In the remaining 29 patients LVEF increased to $32(9) \%$ ( $p<0.0001 v$ baseline). Of the 336 dysfunctional segments, 192 (57\%) (91 hypokinetic and 101 akinetic) improved function of at lest 1 point, 141 were unchanged $(42 \%)$, and 3 deteriorated (1\%). The WMSI improved to 1.7 (0.3) ( $\mathrm{p}<0.0001 v$ baseline). A significant linear correlation was found between the number of dysfunctional segments improving wall motion (hibernating myocardium) in each patient and the changes in LVEF $(r=0.76, \mathrm{p}<0.0001)$ and between the reduction (improvement) in WMSI and the changes in $\operatorname{LVEF}(r=-71, \mathrm{p}<0.0001)$.

MYOCARDIAL VIABILITY

PET

Blood glucose concentration measured before the beginning of the hyperinsulinaemic euglycaemic clamp was $6.27(2.6) \mathrm{mmol} / \mathrm{l}$ (range 4-14), and 5.0 (1.8) (range 3-10) during clamp $(\mathrm{p}<0.0001)$. Plasma insulin concentration was 13 (10) $\mathrm{mU} / 1$ at baseline, and 70 (27) during clamp ( $p<0.0001)$. The MRG for all dysfunctional segments was $0.41(0.16) \mu \mathrm{mol} /$ $\mathrm{g} / \mathrm{min}$ (range $0.05-1.0$ ). The MRG was significantly higher in hypokinetic $(0.43(0.16))$ than in akinetic $(0.38(0.15))$ segments $(\mathrm{p}=0.002)$. A total of $286(85 \%)$ dysfunctional segments were PET viable-that is, had MRG $\geqslant 0.25 \mu \mathrm{mol} / \mathrm{min} / \mathrm{g}$. Viability was detected in $167 / 180$ (93\%) hypokinetic and in 123/156 $(79 \%)$ akinetic segments $(p=0.004)$. The mean number of PET viable segments for each patient was 9 (4) (range 0-15).

\section{Dobutamine echocardiography}

During the DE study, the mean (SD) patients' heart rate was $86(10)$ beats/min at baseline and 99 (12) at peak dobutamine infusion $(\mathrm{p}<0.0001)$. Systolic blood pressure was $116(14) \mathrm{mm} \mathrm{Hg}$ at baseline and 119 (11) at peak infusion (NS). Rate-pressure product was 10081 (1640) at baseline and 11756 (2081) at peak infusion $(p<0.0001)$. Five patients developed ventricular bigemini rhythm at dobutamine infusion of $10 \mu \mathrm{g} / \mathrm{kg} / \mathrm{min}$. A total of 171 (51\%) dysfunctional segments were DE viable (166 manifesting inotropic contractile reserve and 5 ischaemia). Viability was detected in $104 / 180(57 \%)$ hypokinetic and 67/156 (43\%) akinetic segments $(p=0.009)$. The mean number of DE viable segments per patient was 6 (3) (range $0-11)(\mathrm{p}=0.0002 v$ PET).

PREDICTION OF LV FUNCTIONAL RECOVERY Segment by segment analysis

PET - Of the 286 PET viable segments, 190 improved function following CABG (positive predictive value $66 \%$ ) and of the 50 deemed non-viable, two improved function (negative predictive value $96 \%$ ). Ninety one of the 163 hypokinetic PET viable segments improved function (positive predictive value 56\%) compared with 99 of the 124 PET viable akinetic (positive predictive value $80 \%, \mathrm{p}<0.0001 v$ hypokinetic) (fig 1). None of the 17 hypokinetic non-viable segments improved function (negative predictive value $100 \%$ ) compared with two of the 32 akinetic non-viable segments (negative predictive value $94 \%$, NS) (fig 1). A significant linear correlation was found between the number of dysfunctional PET viable segments in each patient and the changes in $\operatorname{LVEF}(r=0.65, \mathrm{p}=0.0001)($ fig 2$)$. 


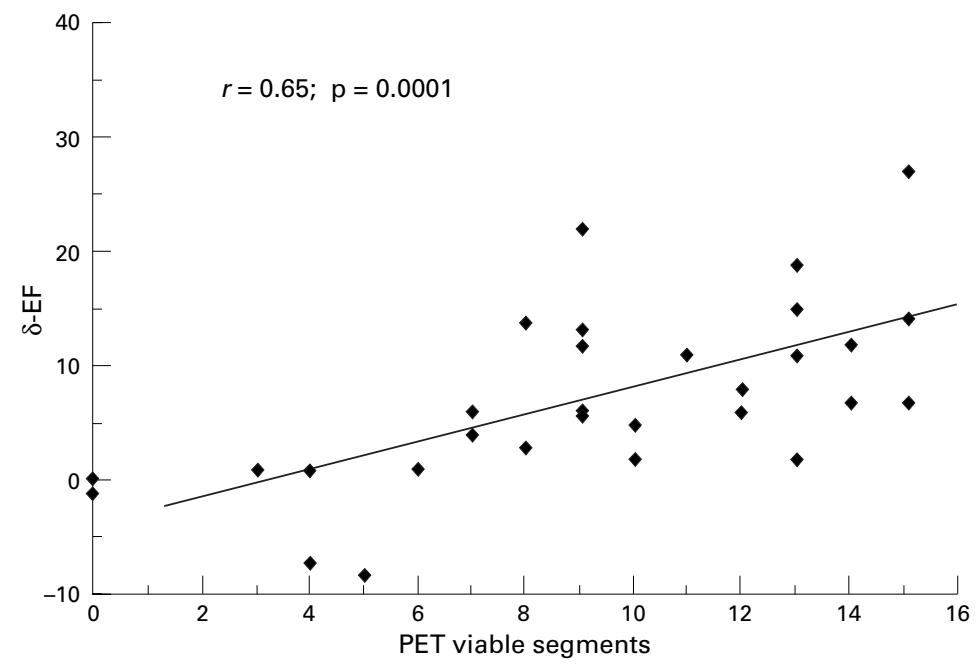

Figure 2 Linear relation between the number of PET viable left ventricular segments and the changes in left ventricular ejection fraction $(\delta-E F)$ following coronary revascularisation.

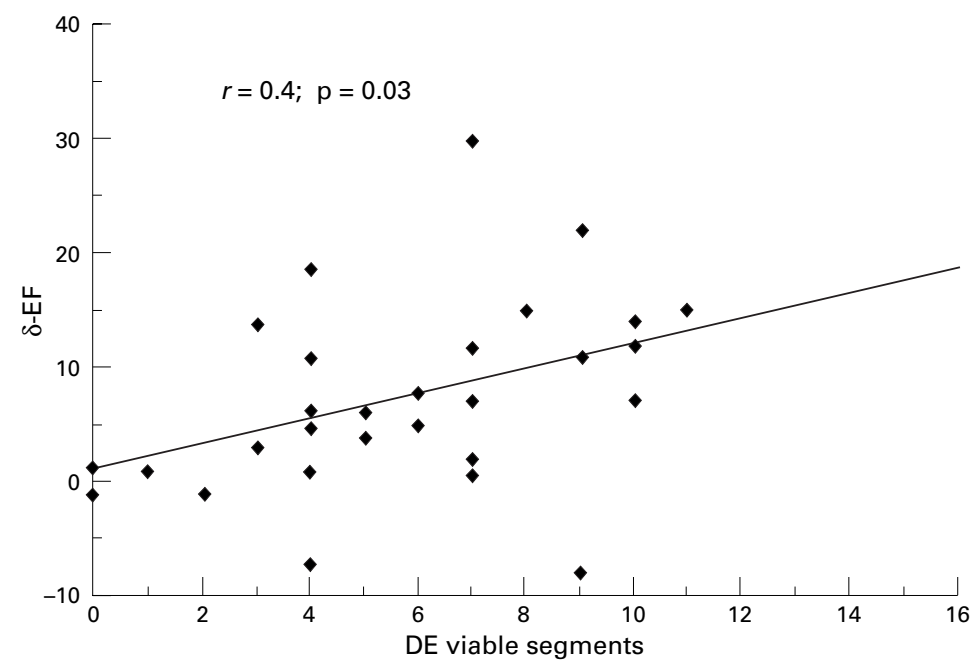

Figure 3 Linear relation between the number of dobutamine viable (DE) left ventricular segments and the changes in left ventricular ejection fraction $(\delta-E F)$ following coronary revascularisation.
Patient by patient analysis

Patients were prospectively divided into two groups: group A (17 patients) in whom there was an increase in $\mathrm{LVEF}>5 \%$ points (mean $13(6) \%$ points), and group B (12 patients) in whom there was an increase in LVEF $\leqslant 5 \%$ points or a deterioration. Patients in group A had a higher incidence of viable dysfunctional segments compared with group B both at PET, (12(3) $v$ 6(4); $\mathrm{p}<0.05)$ and DE (7(3) $v 4(3)$; $\mathrm{p}<0.05)$. Stepwise logistic regression identified the number of PET viable segments as the only predictor of increase in $\mathrm{LVEF}>5 \%$ points $(p=0.005)$ whereas the number of DE viable segments, baseline WMSI, and baseline LVEF were not predictive. To determine the number of PET and DE viable segments in each patient required to obtain an improvement of $>5 \%$ points in LVEF, ROC analysis was performed. This identified eight segments as the best discriminator for PET (sensitivity $88 \%$, specificity $75 \%$, area under the curve $75 \%$ ) and seven segments for DE (sensitivity $47 \%$ specificity $91 \%$, area under the curve 0.69) (fig 5). By using these as cut off points to identify patients likely to have an improvement in LVEF, retrospective analysis demonstrated that PET had identified 15 and DE had identified 8 of the 17 patients with LVEF increase $>5 \%$ points $(p=0.02)$.

\section{Discussion}

In the present study the positive predictive values of PET and DE were comparable, although our figures are lower than those reported by others. ${ }^{9}$ The latter finding could be explained by a number of factors. We studied patients with multiple vessel $\mathrm{CAD}$, severe dysfunction in most LV segments, evidence of $\mathrm{Q}$ wave myocardial infarction, and symptoms of heart failure. There was a high incidence of akinetic segments ( $46 \%$ of all dysfunctional segments), which may have more fibrosis, cellular dedifferentiation, and loss of contractile elements ${ }^{23} 24$ than less dysfunctional myocardium. It is possible, therefore, that such segments may require longer times for functional recovery following revascularisation ${ }^{25}$ and our single postoperative study at six months may have underestimated the amount of recoverable LV dysfunction. In studies where only patients with severe impairment of LVEF were considered, ${ }^{4}$ the positive predictive value of PET was comparable to that found in the present study. The spatial resolution of current PET scanners precludes the assessment of the distribution of a given tracer across the LV wall and it is possible that regions with significant degrees of subendocardial scarring may still show viability with no prospect of recovery of resting contractile function. ${ }^{26}$ In addition, we assessed only the improvement in resting LV function, and it is possible that viable segments not improving resting contractile function may still contribute to the LV function during stress. ${ }^{27}$ Finally, functional recovery following revascularisation may be influenced by both loading conditions and factors influencing coronary flow reserve such as recurrence of 


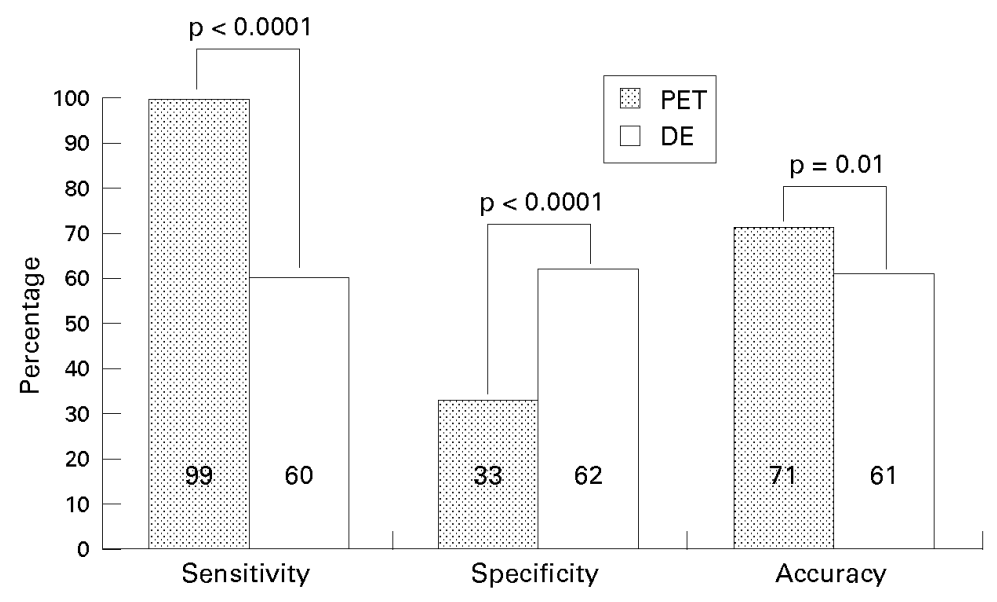

Figure 4 Comparison of overall sensitivity, specificity, and accuracy of PET and DE.

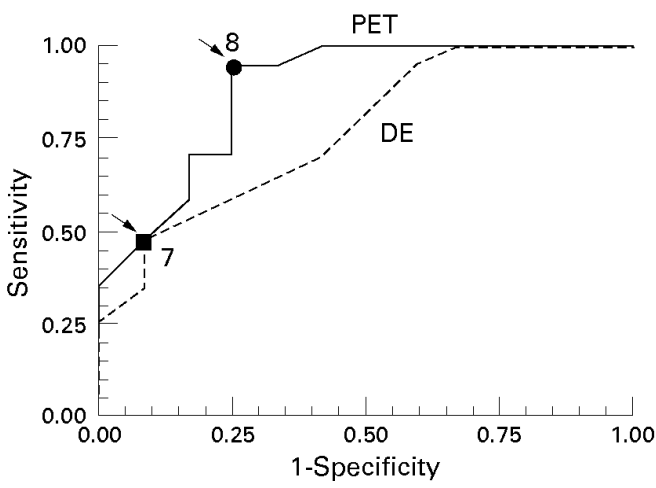

Figure 5 ROC curves demonstrating the sensitivity-specificity pairs for the number of PET viable (solid line) and DE viable (broken line) segments required to obtain improvements in LVEF > 5\% points following $C A B G$. The arrows indicate the operator point for each test associated with the best trade-off between sensitivity and specificity. This was eight for PET (sensitivity 0.88, specificity 0.75) and seven for DE (sensitivity 0.47 specificity 0.91). Note the better performance of PET (area under the curve 0.75) compared with DE (area under the curve 0.69).

stenosis in native vessels and graft patency, which were not addressed in our study.

A significant number of dysfunctional LV segments manifested preserved glucose uptake but did not improve function, thus contributing to the overestimation of viability (low specificity) by PET. This could be explained by the fact that some myocardial regions may retain islands of viable myocardium, but are intermixed with significant amounts of fibrosis and will not improve function after revascularisation. However, in our study the amount of PET viable myocardium in each patient correlated with the improvement in LVEF. Furthermore, even in the absence of improved contractile function, the revascularisation of viable dysfunctional myocardium may attenuate remodelling and LV dilatation, may reduce the propensity to arrhythmia, and may even convey a prognostic benefit. ${ }^{5} 7^{27-29}$

Importantly in this study a significant number of "truly hibernating" myocardial segments (39\% of all recovering segments) did not exhibit inotropic contractile reserve but manifested preserved exogenous glucose uptake, thus the negative predictive value of PET was significantly higher than that of DE. This suggests that in these hibernating segments, while the response to inotropic stimulation was lost, other basic cellular functions involved in FDG uptake and phosphorylation by hexokinase were preserved. ${ }^{30}$ In addition, the negative predictive value of DE decreased significantly in the more dysfunctional segments (akinetic $v$ hypokinetic) and this finding is in agreement with other studies comparing DE with nuclear techniques. $^{10123132}$ Other workers have reported that the overall predictive accuracy of $\mathrm{DE}$ in identifying hibernating myocardium appears comparable to that of nuclear imaging techniques' ${ }^{9}$ however, the severity of regional and global LV dysfunction appears to reduce the diagnostic accuracy of DE. ${ }^{12-14}$ The presence of viable dysfunctional myocardium constitutes an unstable substrate for further cardiac events ${ }^{6}$ and its revascularisation may improve the outcome of patients with severe LV impairment. ${ }^{6728}$ Thus the underestimation of viability by $\mathrm{DE}$ may lead to overlooking patients who might benefit from coronary artery revascularisation.

In patients with severe LV dysfunction and heart failure the lack of response to dobutamine stimulation, despite preserved glucose uptake in myocardium that recovers function following CABG, could be explained by one of the following: (1) the severity of cardiomyocyte alterations (loss and damage of myofibrils and increase in interstitial fibrosis); (2) the extent of impairment of coronary flow reserve; (3) the downregulation of $\beta$ receptors in patients with severe heart failure. ${ }^{9} 1423243334$

Severe damage and loss of myofibrillar components and increase in interstitial fibrosis have been demonstrated in patients in whom contractile function improved after coronary revascularisation. ${ }^{23} 3435$ These changes may be more pronounced in more dysfunctional myocardial segments and could correlate with the lack of contractile reserve on dobutamine stimulation. $^{34}$ Hibernating myocardium is characterised by an impaired coronary vasodilator reserve, ${ }^{36}$ and under these circumstances even the smallest increase in oxygen requirement, such as that demanded by low dose dobutamine infusion, could not be met in some patients, ${ }^{9}$ thus resulting in ischaemia and inability to increase contractile function. ${ }^{937}$ Finally, patients with severe LV dysfunction and heart failure undergo neurohormonal changes that result in downregulation of myocardial $\beta_{1}$ adrenoreceptors ${ }^{33}$ and this could potentially reduce the myocardial sensitivity to dobutamine response.

CLINICAL IMPLICATIONS

Because global LV function is an important prognostic indicator in patients with ischaemic heart failure, ${ }^{38}$ we sought to identify the predictors of meaningful improvements in LVEF on a patient by patient basis. The amount of PET viable myocardium was the only independent predictor of improvement in LVEF $>5 \%$ points. DE missed nine (patients with $<7$ DE viable segments) of the 17 patients who had significantly improved LVEF 
and eight of these patients were correctly identified by PET (had > 8 PET viable segments). However, eight of the nine patients with significant viability ( $>7$ segments) at DE had a significant improvement in LVEF. On the basis of these results we propose a strategy for the investigations of patients with postischaemic heart failure and CAD amenable to CABG. DE should be used as the first screening test for the presence of significant viability. However, because of the high false negative rate shown by this technique, PET should be performed in patients with negative DE. As the number of patients studied is relatively small, the indications provided by our study should be interpreted with the necessary caution. Finally, both DE and PET indicated that a significant mass of viable myocardium is required to achieve a significant improvement in LVEF following CABG. This finding underlines the importance of accurate preoperative assessment of viability particularly in patients with very poor LV function who have the highest perioperative risk. ${ }^{39}$

\section{STUDY LIMITATIONS}

We used a low dose dobutamine protocol and higher doses may have unveiled more ischaemia, which has been shown to be a strong predictor of recovery of function. ${ }^{40}$ Despite achieving a significant increase in the patient's heart rate and rate-pressure product, which are determinants of myocardial oxygen demand, we detected ischaemia in five of $336(1.5 \%)$ dysfunctional segments. However, the 5 and $10 \mu \mathrm{g} / \mathrm{kg} / \mathrm{min}$ protocol adopted in our study is widely used ${ }^{12} 182241$ thus allowing meaningful comparison of results. One study comparing different doses of dobutamine ${ }^{40}$ demonstrated that most (94\%) dysfunctional segments manifesting biphasic response at dosages $>10 \mu \mathrm{g} / \mathrm{kg} /$ min demonstrate contractile reserve at dosages between 5 and $7.5 \mu \mathrm{g} / \mathrm{kg} / \mathrm{min}$. Finally, there was a high incidence of complications with dobutamine at $10 \mu \mathrm{g} / \mathrm{kg} / \mathrm{min}-17 \%$ of patients developed significant ventricular arrhythmias.

We did not use a digitised technique for the analysis of the echo images and this could have led us to overlook subtle changes in wall motion during dobutamine infusion. However, the diagnostic accuracy of the digitised analysis appears comparable to that of the videotape approach. ${ }^{42}$

The impact of revascularisation of viable myocardium on long term prognosis was not addressed by this study, and therefore indications on the appropriate treatment of patients with postischaemic heart failure cannot be extrapolated from our results. However, LVEF has been demonstrated to be a strong prognostic determinant in patients with CAD and heart failure and it could be that its improvement may be associated with prognostic benefits.

This paper was presented at the American College of Cardiology meeting, Anaheim, California, USA, 16-19 March 1997.

D Pagano is supported by a Sheldon Clinical Research D Pagano is supported by a Sheldon Clinical Research
Fellowship of the West Midlands Health Authority. The authors Fellowship of the West Midlands Health Authority. The authors
express their gratitude to Miss T Ryan for the acquisition of the express their gratitude to Miss T Ryan for the acquisition of the
echocardiograms, to the staff of the Nuclear Medicine Department of the Queen Elizabeth Hospital for the acquisition and analysis of the radionuclide ventriculography tests, to Dr P Jordan and Dr M Pitt for their help in the analysis of the echo images, to the radiochemists and the radiographers of the MRC Cyclotron Unit for their help in the acquisition of the positron emission tomography data. Special thanks to Ms H Boyd for the help and expertise in the analysis of the PET data and to Dr P Davies from the school of Mathematics and Statistics of the University of Birmingham for advise in the statistical analysis of the data.

1 Diamond G, Forrester J, deLuz P, et al. Post-extrasystolic potentiation of ischaemic cardiomyopathy by atrial stimulapotentiation of ischaemic cardiom

2 Rahimtoola S. Coronary bypass surgery for chronic angina-1981: a perspective. Circulation 1982;65:225-41.

3 Dreyfus G, Duboc D, Blasco A, et al. Myocardial viability Dreyfus G, Duboc D, Blasco A, et al. Myocardial viability
assessment in ischaemic cardiomyopathy: benefits of coronary revascularisation. Ann Thorac Surg 1994;57: $1402-8$

4 vom Dahl J, Eitzman DT, al Aouar ZR, et al. Relation of regional function, perfusion, and metabolism in patients with advanced coronary artery disease undergoing surgical revascularization. Circulation 1994;90:2356-66.

5 Gioia G, Powers J, Heo J, et al. Prognostic value of rest-redistribution tomographic thallium-201 imaging in ischaemic cardiomyopathy. Am f Cardiol 1995;75:759-62.

6 Lee S, Marwick T, Cook S, et al. Prognisis of patients with left ventricular dysfunction, with and without viable myocardium after myocardial infarction. Relative efficacy myocardium after myocardial infarction. Relative efficacy 90:2687-94.

7 Pagley P, Beller G, Watson D, et al. Improved outcome after coronary artery bypass surgery in patients with ischemic cardiomyopathy and residual myocardial viability. Circulation 1997;96:793-800.

8 Dilsizian V, Bonow RO. Current diagnostic techniques of assessing myocardial viability in patients with hibernating and stunned myocardium. Circulation 1993;87:1-20.

9 Bonow R. Identification of viable myocardium. Circulation 1996;94:2674-8.

10 Baer M, Voth E, Deutsch J, et al. Assessment of viable myocardium by dobutamine transesophageal echocardiography and comparison with fluorine-18-fluorodeoxyglucose positron emission tomography. $\mathcal{F}$ Am Coll Cardiol 1994;24:343

1 Hepner A, Bach S, Bolling S, et al. A positive dobutamine stress echocardiogram predicts viable myocardium in ischaemic cardiomyopathy: a comparison with PET ischaemic cardiomyopathy: a comparison

12 Perrone-Filardi P, Pace L, Prastraro M, et al. Assessment of myocardial viability in patients with chronic coronary myocardial viability in patients with chronic coronary raphy versus dobutamine echocardiography. Circulation 1996;94:2712-19.

13 Pirelli S, Crivellaro W, Faletra F, et al. Dobutamine stress echocardiography and rest thallium-201 scintigraphy in patients with previous myocardial infarction and single coronary artery lesion: prediction of functional recovery after revascularisation [abstract]. $\mathrm{f} \mathrm{Am}$ Coll Cardiol 1995;25(suppl):340A.

14 Gerber B, Vanovershelde J-L, Bol A, et al. Myocardial blood flow, glucose uptake, and recruitment of inotropic reserve in chronic left ventricular ischemic dysfunction. Implications for the pathophysiology of chronic myocardial hibernation. Circulation 1996;94:651-9.

15 Pagano D, Camici P, Townend J, et al. Coronary artery bypass grafting for congestive heart failure [abstract]. Circulation 1996;94(suppl):I-232.

16 Zaret BL, Wackers FJ. Nuclear cardiology (second of two parts). N Engl F Med 1993;329:855-63.

17 Bland M, Altman D. Statistical methods for assessing agreement between two methods of clinical measurements. Lancet 1986;i:307-10.

8 Segar D, Brown S, Sawada S, et al. Dobutamine stress echocardiography: correlation with coronary lesion severity as determined by quantitative angiography. $\mathcal{F} \mathrm{Am}$ Coll Cardiol 1992;19:1197-202.

19 Marinho N, Keogh B, Costa D, et al. Pathophysiology of chronic left ventricular dysfunction. New insights from the measurement of absolute myocardial blood flow and glucose utilisation. Circulation 1996;93:737-44.

20 Fath-Ordoubadi F, Marinho N, Keogh B, et al. Value of positron emission tomography in predicting functional recovery following coronary revascularisation: effect of baseline wall motion score and ejection fraction [abstract]. Eur Heart f 1995;16(suppl): 129 .

21 Metz C. Basic principles of ROC analysis. Semin Nucl Med 1978;8:283-98.

22 Bax J, Cornel J, Visser F, et al. Prediction of recovery of myocardial dysfunction after revascularization. Comparison of fluorine-18 fluorodeoxyglucose/thallium SPECT. Thallium-201 stress-reinjection and dobutamine echocardiography. F Am Coll Cardiol 1996;28:558-64.

23 Ausma J, Cleutjens J, Thone' F, et al. Chronic hibernating myocardium: interstitial changes. Mol Cell Biochem 1995; 147:35-42.

24 Ausma J, Furst D, Shivalkar B, et al. Molecular changes of titin in left ventricular dysfunction as a result of chronic hibernation. $\mathcal{F}$ Mol Cell Cardiol 1995;27:1202-12.

25 Camici PG, Wijus W, Borgers M, et al. Pathophysiological mechanisms of chronic reversible left ventricular dysfunction due to coronary artery disease (hibernating myocartion due to coronary artery disease
dium). Circulation 1997;96:3205-14. 
26 Armstrong W. "Hibernating" myocardium: asleep or part dead? $\mathcal{F}$ Am Coll Cardiol 1996; 8:530-5.

27 Kaul S. There may be more viability that meets the eye! $\mathrm{Cir}$ culation 1995;92:2790-93.

28 Di Carli M, Davidson M, Little R, et al. Value of metabolic imaging with positron emission tomography for evaluating prognosis in patients with coronary artery disease and left ventricular dysfunction. Am F Cardiol 1994;73:527-33.

29 Eitzman D, Za A, Kanter HL, et al. Clinical outcome of patients with advanced coronary artery disease after viability studies with positron emission tomography [see comments]. F Am Coll Cardiol 1992;20:559-65.

30 Camici P, Ferranini E, Opie L. Myocardial metabolism in ischaemic heart disease: basic principles and applications to imaging by positron emission tomography. Progr Cardiovasc Dis 1989;32:217-38.

31 Lucignani G, Landoni C, Mengozzi G, et al. Relation between dobutamine transthoracic echocardiography, ${ }_{99 \mathrm{~m}} \mathrm{Tc}-\mathrm{MIBI}$ and ${ }^{18} \mathrm{FDG}$ uptake in chronic coronary artery disease. Nuclear Medicine Communications 1995;16:548-57.

32 Panza J, Dilsizian V, Laurienzo J, et al. Relation between thallium uptake and contractile response to dobutamine. Implications regarding myocardial viability in patients with chronic coronary artery disease and left ventricular dysfunction. Circulation 1995;91:990-8.

33 Bristow M, Ginsburg R, Minoke W, et al. Decreased catecholamine sensitivity and B-adrenergic-receptor density in failing human hearts. $N$ Engl F Med 1982;307:20521 .

34 Pagano D, Bonser R, Townend J, et al. Histopathological correlates of dobutamine echocardiography in hibernating myocardium [abstract]. Circulation 1996;94(suppl):I-231.
35 Depre' C, Vanoverschelde J, Melin J, et al. Structural and Depre' C, Vanoverschelde J, Melin J, et al. Structural and
metabolic correlates of the reversibility of chronic left venmetabolic correlates of the reversibility of chronic left ven-
tricular ischemic dysfunction in humans. Am f Physiol tricular ischemic dysf

36 Vanoverschelde JJ, Wijns W, Depre' C, et al. Mechanism of chronic regional postischaemic dysfunction in humans. New insights from the study of noninfarcted collateraldependent myocardium. Circulation 1993;87:1513-23.

37 Chen C, Chen L, Prada J, et al. Incremental doses of dobutamine induce a biphasic response in dysfunctional left ventricular regions subtending coronary stenoses. Circulation 1995;92:756-66.

38 Cohn J, Johnson J, Shabetai R, et al. Ejection fraction, peak exercise oxygen consumption, cardiothoracic ratio, ventricular arrhytmias, and plasma noreepinephrine as determinants of prognosis in heart failure. Circulation 1993; 87(suppl):VI-5-16.

39 Hochberg M, Parsonnet V, Gielchinsky I, et al. Coronary artery bypass grafting in patients with ejection fractions below forty percent. F Thorac Cardiovasc Surg 1983;86: 519-27.

40 Afridi I, Kleiman N, Raizner A, et al. Dobutamine echocardiography in myocardial hibernation. Optimal dose and accuracy in predicting recovery of ventricular function after coronary angioplasty. Circulation 1995;91:663-70.

41 La Canna G, Alfieri O, Giubbini R, et al. Echocardiography during infusion of dobutamine for identification of reversbly dysfunction in patients with chronic coronary artery disease. F Am Coll Cardiol 1994;23:617-26.

42 Castini D, Gentile M, Ornaghi M, et al. Dobutamine echocardiography: usefulness of digital image processing. Eur Heart F 1995;16:1420-4.

\section{IMAGES IN CARDIOLOGY}

\section{Onion skin aneurysm of the aortic arch}

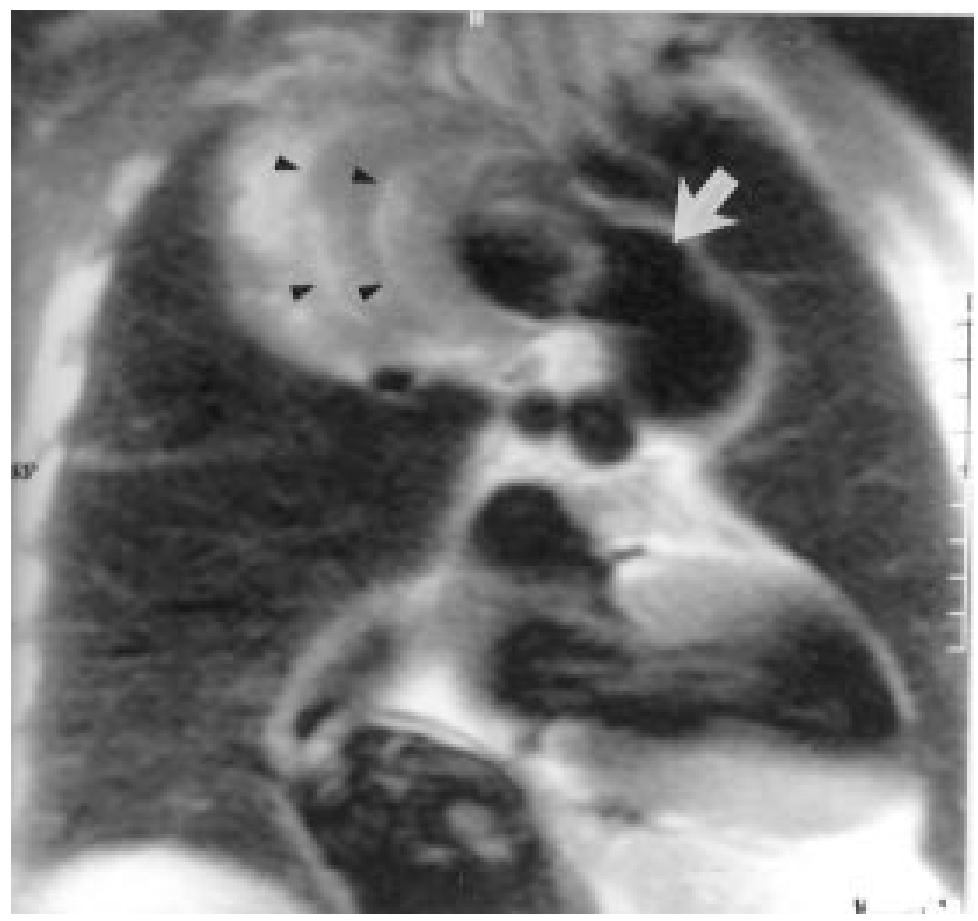

A 56 year old man who had had a stroke 10 years previously presented with transient ischaemic attack (TIA). Chest radiography showed a large mass in the right upper hemithorax measuring $12 \times 6 \mathrm{~cm}$. Because of chronic renal failure magnetic resonance imaging (MRI) was performed. The coronal MRIs (dark blood T2 weighted turbo spin-echo MRI) showed a saccular aneurysmatic protrusion of the aortic wall originating from the right border of the aortic arch. A large part of the aneurysm was not perfused and was thrombosed in layers (arrowheads). The perfused lumen (arrow) of the true aneurysm measured $3 \times 4 \mathrm{~cm}$. The TIA occurred because of the multiple sources of emboli and the carotid stenosis. Oral anticoagulation was prescribed.

T CHATTERJEE M F MÜLLER B MEIER 